Extensive studies were done on the bacteriology of the tap water, the dialysate from the supply tank onwards, and the patient's blood. The rigors were not related to bacterial counts in blood, tap water, dialysate, or Kiil fluid, nor to the type of organism detected: nor were they related to the state of the Kiil boards, the rubber gaskets, the procedure of removing formalin, or the techniques of sterilizing dialysers and the supply system.

The problem was solved when the emergent saline from the dialyser blood compartment was searched for protein instead of viable bacteria. Spectrophotometric examination detected a protein peak at $278 \mathrm{~m} \mu$ from this fluid, and none from tap water, dialysate, or the sterilizing solutions used. The concentration of this protein correlated with the severity of the rigors in different patients. Search back to the initial preparation of the membranes revealed a fluctuating bacterial count in the tank in which they were washed. Bacteria adhering to the membranes were efficiently killed by formalin, but inadequately washed off the membranes by the saline flush.

As soon as dry membranes were used to build the dialysers, the numbers of and episodes of hyperpyrexia were markedly reduced and in the following 4,160 dialvses, only 49 unexplained pyrexias have occurred.

Renal Unit,
Auckland Hospital, New Zealand

E. A. BowIE

\section{Salicylates and Papillary Necrosis}

SIR,-Dr. T. W. Steele's (31 October, p. 306) main criticism of our paper (5 September, p. 559) is that we should adopt a more objective approach to the question: are salicylates responsible for renal damage in man?

In reply to the spec:fic points in his letter about the effects of diuretic substances, we deliberately did not apply statistics to the group shown in Tables III and IV because we did not like to add up results in the different small groups. If, however, Dr. Steele feels that statistics should be applied the fact that 31 of 80 rats in the dehydrated groups fed on aspirin-containing mixtures developed papillary necrosis compared with 6 of 40 in the rats on a constant water diuresis and aspirin-containing $m$ :xtures shows a highly significant difference $(P<0.005)$. If the groups of rats in Table IV which were dehydrated but given acetazolamide and sodium bicarbonate are compared with dehydrated rats in Table III the difference is again signifirant $(\mathrm{P}<0.025)$. The diuretic action of caffeine s'ould if anvthing diminich the eferts of dehydration in the groups in Table III. In fact the only group in Table III which anoroaches significant difference from the other smoll grouns is the $\mathrm{A}+\mathrm{C}$ gro'p $(P<0 \cdot 1>0.05)$-with Yates correction). This to gether with the fact that the dose of aspirin is higher in the $\mathrm{A}+\mathrm{C}$ group compared to the $\mathrm{A}+\mathrm{P}$ group suggests that "caffeine may reduce the nephrotoxicity of aspirin" as we state in our discussion (5 September, p. 559).

Most of Dr. Steele's points relate to our discussion in which we drew attention to the association between renal damage and aspirin intake in man. We did not claim that this proved anything. The mere fact that papillary necrosis has been reported in patients who are said to have taken only aspirin is of interest. No such data are available for phenacetin in man, but nonetheless it is very widely believed that phenacetin causes papillary necrosis in man. What more objective approach is possible in man? A long term epidemiological study is in progress in Switzerland. This may be the right line of approach but is a doctor entitled to let his patients continue to take tablets and observe deterioration in function over many years until papillary necrosis develops when he can demonstrate that the analgesics which they are taking produce papillary necrosis in animals?

Perhaps the recent demonstration that salicylates are concentrated within the renal papilla will carry more weight with physiologically inclined nephrologists.' Dr. K. G. Koutsaimanis and Professor $H$. de Wardener (17 October, p. 131) seemed to attach great importance to Bluemle and Goldberg's observation that $N$-acetyl-p-aminophenol (paracetamol) is concentrated in the papilla We are inclined to look at things more from the morphological point of view and are more impressed when we see necrosis than by a concentration gradient in the papilla of an animal.

The last paragraph of Dr. Steele's letter implies that in demonstrating that salicylates produce papillary necrosis in rats we were not adopting an objective approach to the question: do salicylates cause papillary necrosis in man? While this may be so animal experiments form the basis of testing all new drugs and the Dunlop Committee or any similar body would be unlikely to accept a new drug in 1970 if it produced papillary necrosis in over a third of the animals tested. Should we then adopt quite different methods of testing old drugs and new drugs?

We think that the fact that salicylates will produce papillary necrosis in animals, and that phenacetin in the same dose will not, is at least suggestive that salicvlates contribute to the development of papillary necrosis in patients who take aspirin, phenacetin, and caffeine and aspirin, paracetamol, and caf feine mixtures.-We are, etc.

RANJIT S. NANRA Priscilla Kincaid-SMith

Medical Renal Unit and University of Melbourne Department of Medicine,

cic-ia, Austral : Gault, M. H., Abstract, American Society of
Nephrology, 1970, p. 28.

\section{Phenacetin Nephropathy}

SIR,-The choice of the title "Phenacetin Nephropathy" rather than "analgesic nephropathy" in our paper was deliberate (17 October, p. 131). We avoided the term "analgesic nephropathy" for two reasons. The first is that in our opinion the facts now overwhelmingly incriminate phenacetin as the cause of analgesic nephropathy. It is therefore misleading to continue to use the $\rightarrow r m$ analgesic nephropathy. Secondly the use of the term analgesic nephropathy un justifiably includes other analgesics such as caffeine and codeine against which no accusations have so far been made that in the absence of phenacetin they may cause papillary necrosis in man. For instance, Nanra Fairley, and Kincaid-Smith ${ }^{1}$ have pointed out that codeine phosphate is not harmful even to patients known to have papillary necrosis due to phenacetin-containing analgesics.
We are astonished that Dr. L. F. Prescott (21 November, p. 493) continues to support his hypothesis that aspirin causes papillary necrosis in man. In our paper we reported that the consumption of aspirin in Great Britain in 1967 was $3,020,000 \mathrm{~kg}$ and that during the same year the consumption of phenacetin was $540,000 \mathrm{~kg}$. Therefore the annual consumption of aspirin ingested without phenacetin is of the order of $2,000,000 \mathrm{~kg}$ per year.

Nevertheless, this annual avalanche of aspirin has yielded only two possible victims with papillary necrosis (Dr. R. M. Murray and others 27 February, p. 479). On the other hand, extrapolating from our own experience of 18 patients suffering from phenacetin nephropathy in seven years we concluded that the total incidence of new patients presenting with phenacetin nephropathy in England and Wales is unlikely to be much less than 500 per year. After parusing these figures, Dr. Prescott comes to the conclusions that "Although abuse of mixed anaigesics is associated with papillary necrosis, it is most unlikely that phenacetin itself plays a major aetiological role. The saliculates and pyrazolones taken with it are much more likely to be the culprits". For our part we have been so impressed by the almost total lack of any evidence that in man aspirin causes papillary necro is that, like Dr. R. M. Murray (and others), we advise our patients suffering from phenacetin papillary necrosis to take aspirin, if their need for analgesic continues after they have ceased taking phenacetin-containing tablets. The mprovement in these patients' health and ronal function upon stopping the ingestion of phenacetin-containing tablets has been the same as those who stopped taking all forms of analgesics.

We feel that Dr. P. Kincaid-Smith's views' are close to our own. Nevertheless she continues to support the contention that, in addition to phenacetin, aspirin and some other analgesics may also cause papillary necrosis in man. She mentions that she has seen patients with phenacetin papillary necrosis who have had a severe deterioration of renal function shortly after the patients have returned to taking large quantities of nonphenacetin analgesics. In support of this view, Dr. Murray and colleagues report that an unstated number of their patients in whom papillary necrosis developed while ingesting phenacetincontaining tablets had a continued deterioration of renal function subsequently if they continued to take the same tablets from which, however, phenacetin had now been removed. This, of course, is not evidence that papillary necrosis is due to non-phenacetin analgesics. It can only be put forward as evidence that in a patient with phenacetin papillary necrosis the ingestion of such tablets may cause a deterioration of renal function. On the other hand, this suggestion contrasts with our own experience which has been mentioned above. It also contrasts with the findings of Dr. Murray and his colleagues themselves, who reported that "No difference in prognosis could be found between those who abstained from analgesics entirely and those who took small doses of paracetamol or aspirin when necessary". It must also be pointed out that the patients described by Dr. Nanra and colleagues and Dr. Murray and colleagues already knew that their kidneys had been partially destroyed by the ingestion of phenacetin-containing tablets. Patients with phenacetin nephropathy are wellknown to conceal their habit and to underestimate their ingestion of phenacetin, particularly when they susnect that their doctor is trying to relate this ingestion to their symptoms. We would suggest that it is very probable that these patients' statement that they subsequently ingested nonphenacetin-containing drugs was probably untrue, 
as it was made after they had been warned of the dangers of phenacetin.

Dr. Kincaid-Smith also states that in Australia paracetamol was substituted for phenacetin in the A.P.C. mixtures in the National Health Service listing about eight years ago, but nevertheless analgesic nephropathy is still very cornmon. This statement suggests either that Dr. KincaidSmith thinks that paracetamol is as destructive as phenacetin, a suggestion which we believe is probably correct, though in Great Britain the evidence is only just beginning to appear, or it suggests that Dr. Kincaid-Smith thinks that beause phenacetin was removed from the National Health Service listing it therefore should have disappeared from the Australian scene. One gathers however that this is far from the truth. For instance, Purnell and Burry ${ }^{2}$ in a survey in a country town in Queensland found that the average weekly phenacetin consumption for a person over 15 years old was $1.845 \mathrm{~g}$. Only $37 \%$ of the phenacetin sold came from chemists and only a very small proportion of this was sold via prescriptions. They concluded that "the recent removal of phenacetin-containing drugs from the free-list of phenacetin benefits in Australia is unlikely to have any appreciable eff :ct ucon the consumption of phenacetincontaining analgesics by the community". The situation seems to be analogous to our own. We found that though phenacetin has now heen removed from mo:t proprietary preparations this could have little effect on the total ingestion of phenacetin as fourfifths of the phenacetin ingested is in the form of B.P. and B.P.C. preparations.

We wo:ld submit that the case against phenacetin is formidable, and we would once more plead that it should be available only on a doctor's prescription.-We are, etc.,

H. E. DE WARD TNER

Department of Medicine

Charing Cross Hospital

Medical School,

Fulham Hospitat,

ondon W.

Nanra, R. S., Fairley, K. F., and Kincaid-Smith, P. Australasian Annals of Medicine, 1970, 19, 195. Australia, 1967, 2, 389 .

\section{Diabet:c Ketoacidosis and Influenza}

Sir, - I was interested in the communication by Dr. P. J. Watkins and others (10 October p. 89) about the marked incidence of hypok laemia in diabetic ketoacidosis provoked by influenzal illness.

I would like to suggest one possible mechnaism for potassium loss in such instances-namely, through the nasal secretions, if there is rhinorrhoea and or pneumonia. Very lit le information is available in the literature regarding the nature of the nasal mucus, mainly because it normally exists only as an extremely thin laver on the mucosal surface. ${ }^{1}$ Ingelstedt and Ivstam injected of fluorescin intravenously and found none in the nasal secretion They concluded that the mucin gland alone were the source of the normal nasa mucus." However, there is a general agreement that in inflammatory conditions, it consists to a large extent of an exu-tate."

Information regarding the electrolyte concentration in the normal nasal secretion is likewise virtually non-existent. Proetz stated that the constituents of the nasal mucus are generally 2.5 to $3 \%$ mucin, $1-2 \%$ salts, and $95-97 \%$ water. ${ }^{3}$ Potter et al.,' reporting on the analysis of whole pulmonary secretion in laryngectomized patients, obtained a potassium concentration of $13.2 \pm 5.4 \mathrm{mEq}$ per gram of secretion. Two years ago I had the chance to analyse a sample of my nasal secretion, while suffering from an attack of coryza. Using the atomic absorption method the potassium concentration in that sample was $26 \mathrm{mEq} / 1$.

The volume of mucus secreted per day through the nasal mucosa is estimated to be more than a litre.' With rhinorrhoea this volume is obviously multiplied many times, and if we add the volume of the whole pulmonary secretion produced in pneumonia, as was the case in several of Dr. Watkins's patients, the net loss of potassium may be significant, especially if the dietary intake is low.-I am, etc.

RiDHA HAJJAR

Wadsworth Veterans Administration Hospital

Los Angeles, California, U.S.A.

Proctor, D. F., in Handbook of Physiology, Section 3, Respi a:ion, 1. n 309. W'ashington,
American Physiological Society, 1964 .

Ingelstedt, S., and Irstam, B., Acta Otolaryn logica, 1949, 37, 446.

Proetz, A. W., Essays on the Applied Phystology of the Nose, $2 \mathrm{n} 1$ edn., St. Louis, Annals Potter, J. L., Maith ws.

Spector, S., Annals of the New York, J., and of Sciences, 1963, 166, 692 .

\section{Exposure Treatment for Phobias}

SIR,-We were most interested to read the article by Dr. J. P. Watson and others (2 January, p. 13). It seems likely that the authors' findings that treatment with prolonged exposure produced better results in less time than other treatments so far reported for chronic phobic disorders will receive wite acceptance and will arouse a great deal of enthusiasm. This, we suggest, would be unfortunate, since whether or not prolonged exposure is in fact dramatically effective in treatment of chronic phobic disorders is certainly not established by the study under discussion.

The study is uncontrolled, the number of patients treated is small, and the selection is biased. As long ago as 1957, Foulds ${ }^{1}$ reported that authors claimed success in psychiatric treatment in $85 \%$ of uncontrolled studies compared to $19^{\circ} \%$ of studies in which controls were used; apparently, the moral has yet to be learnt.

The results of this study cannot be accepted valid ant conclusive as there are no parameters available to determine the effect of passage of time. suggestion, placebo effects, bias, and overemthusiasm-which is so of ten associated with a new type of treatment. At the same time a retrospective comparicon can not be made hetween the results of this inappropriately conducted trial and patients treated previously, as in this case it cannot be assumed that groups are comparable. Dr. Watson and colleagues' results would have been more conclusive and convincing if they had eliminated these shortcomings by the basic procedure of employing controls and random allocation between groups.

The flooding and prolonged exposure method are attractive because of their sim- plicity and their satisfactory administration by novices, whereas desensitization requires skill and practice to be effectively performed. As these methods will be employed more frequently, one should be aware of certain aspects of considerable theoretical and practical importance which has not been considered in clinical evaluation. Duration of the treatment session and, closely related to this, the point at which the treatment session can be terminated, are important because theoretically one may expect that premature termination of a treatment session (that is, when the patient is still at an exceedingly high level of arousal) may result in an exacerbation rather than a reduction in anxiety. This possibility is raised both by Eysenck's" theory of the incubation of fear responses and can also be deduced from the maximal habituation theory proposed by Lader and Mathews's ${ }^{3}$ and some experimental evidence for supporting these sensitizing interpretations is accumulating (Fazio'). The other factors which determine the efficacy of response prevention include the extent to which responses have been overtrained, the amount of response prevention given, the intensity of the fear underlying the avoidance response, and the necessity for the sub;ect to cease fear behaviour and engage in relaxation behaviour during response prevention if subsequent rapid extinction of avoidance response was to occur (Baum"). To enhance the efficacy of response prevention and overcome the problem of exacerbation of anxiety, the use of short-acting barbiturate (thiopentone) in doses small enough to produce relaxation has been suggested (Hussain ${ }^{6}{ }^{7}$ ). Thanks to this pharmacological aid the anxious neurotic has less difficulty exploring and discussing his fears because of the relaxed state produced by the barbiturates and has protection against the more disagree?ble manifestation of anxiety. Its use causes reduction in critical sense and an enhencement of rapport. Aggressive feelings which would terrify the individual in his normal state can be expressed without excessive anxiety and emo:ional experience can be relieved. In this state, the patient accepts suggestions more readily, can visualize the versions of the situations suggested more realistically, and experiences the appropriate emotional responses. It has the additional advantage of obviating the panic reaction due to the patient's fear of death in the course of therapy. As well, the use of thiopentone abolishes the possibility of exacerbation of anxiety to premature termination of the treatment

In short, treatment with response prevention (flooding, exposure) which is arousing a great deal of enthusiasm is still in the experimental stages and its mode of action controversial; and as there appears to be some danger associated with its uce one should be cautious against the uncritical acceptance of the technique and reports of its successes and failures.-We are, etc.,

M. Z. HuSSAIN

Psychiatric Drpartment,

D partment of Public Health,

Province of Saskatch cwan

1 Foulds, G. A., Journal of Mental Science, 1958

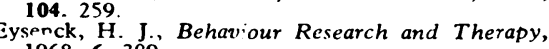
Eysenck, H. J., Behaviour Research and Therapy,
$1958,6.309$. Research and Therapy, 1968, 6, 411 . 